\title{
Scaling Up Renewables Through Regional Planning and Coordination of Power Systems in Africa-Regional Power System Planning to Harness Renewable Resources and Diversify Generation Portfolios in Southern Africa
}

\author{
Dudu Hadebe $^{1} \cdot$ Ahmed Hansa $^{1} \cdot$ Caswell Ndlhovu $^{1} \cdot$ Mbulelo Kibido $^{1}$
}

Published online: 23 October 2018

(C) The Author(s) 2018

\begin{abstract}
Purpose of Review Southern Africa has an abundance of renewable energy resources, yet $\sim 40 \%$ of its inhabitants do not have access to electricity. This paper summarizes the literature scan to understand the energy access challenge in the region, explores possible solutions, and examines the extent of planning and coordination at regional level aimed at exploiting energy from renewable energy sources and diversifying energy portfolios.

Recent Findings The paper finds that the inhibiting factors are shortcomings in regional institutions and at government level, financial scarcity, inadequate grid, lack of interconnection among the member states, and a low skills base for renewable energy integration.

Summary The paper recommends empowering regional institutions to make binding decisions on regional energy planning; government commitment to renewable energy projects; innovative funding mechanisms; interconnecting all Southern African Power Pool (SAPP) countries; strengthening the existing interconnectors using high-voltage direct current (HVDC) and highvoltage alternating current (HVAC); accelerating renewable energy targets through hydropower, gradually increasing access by implementing off-grid, mini-grids, national grids, and eventually the regional SAPP grid; and improving skills in collaboration with countries that are experienced in renewable energy.
\end{abstract}

Keywords SADC $\cdot$ SAPP $\cdot$ Renewable energy $\cdot$ Interconnectors $\cdot$ Hydropower $\cdot$ HVDC $\cdot$ Off-grid

\section{Introduction}

Africa has immense untapped renewable energy potential, yet the continent remains largely dark with over 600 million people in sub-Saharan Africa without access to energy [1].

Only $43 \%$ out of a population of 177 million in the Southern Africa region have access to electricity [2••].

This paper examines the latest literature to gain insight into the reasons as to why the region remains dark despite being enriched with renewable energy resources and explores

This article is part of the Topical Collection on Regional Renewable Energy-Africa

Mbulelo Kibido

KibidoM@eskom.co.za

1 Eskom Holdings SOC Ltd, Maxwell Drive, Sunninghill, Sandton, Johannesburg, Gauteng 2157, South Africa proposed solutions to this challenge. It also examines the extent of planning and coordination at regional level aimed at exploiting energy from renewable energy sources and diversifying energy portfolios.

\section{The Role of Regional Institutions}

The Southern African Development Community (SADC) is an intergovernmental organization which was established in 1980. It aims to promote socio-economic, political, security cooperation, and integration among the 15 member states comprising of Angola, Botswana, DRC, Lesotho, Madagascar, Malawi, Mauritius, Mozambique, Namibia, Seychelles, South Africa, Swaziland, Tanzania, Zambia, and Zimbabwe [3].

The Southern African Power Pool (SAPP) is a regional cooperation organization formed in 1995 by SADC and made 
up of utilities from 12 SADC member countries. SADC member countries not participating in SAPP are oceanic countries of Madagascar, Mauritius, and Seychelles [4].

SAPP's mandate is to coordinate the planning and operation of the electrical power system among its member utilities and to provide a forum for regional solutions to electrical energy problems [4]. Delivery on the SAPP's mandate is achieved through the SAPP Planning sub-committee which conducts a biennial review of the integrated generation and transmission plan with the aim of exploring areas where cost savings could be derived [5].

As per the 1996 Protocol on Energy [6], a provision was made by SADC for utilization of renewable energy, foreseeing that its role will be vital as the region develops. Member states were advised to cooperate on the development and usage of renewable energy sources in the region. This was further supported by SAPP in their interview with the Power Journal, ESI Africa, that renewable energy is a cost-effective supply alternative for the region [7].

In 2001, at a meeting held by SADC Heads of State and Governments, strategies and targets were defined in the energy sector aimed at promoting the extension of grid interconnections to encompass all member countries by 2012 , to facilitate market integration by coordinating policies and regulations by 2006 , and to make modern forms of energy available to majority of rural communities by 2018 [3].

SADC countries have plans to harness energy potential from various renewable technologies. SADC has a vision of $100 \%$ renewable energy by 2050 . In order to achieve this, the share of renewable energy in the regional grid is targeted to increase from $21 \%$ in 2017 to $37 \%$ by 2027 [8] .

\section{Challenges and Proposed Solutions}

Although SADC recognizes that the development of renewable energy is a matter of priority to address the energy needs of the region [9], challenges ranging from financial, technical, institutional, and political still exist as detailed below.

\section{Financial}

It is estimated that Africa requires US $\$ 100$ billion a year in climate change initiatives including renewable energy projects; however, a number of countries in sub-Saharan Africa are classified as poor with higher proportions of the population living at under US\$1.90 per day [10]. Currently, most of the funds directed towards renewable energy projects is provided by means of donor funding and, in most cases, is aimed at small-scale and pilot projects to demonstrate what can be done.

Funding initiatives from international agencies is a major feature in many activities concerning renewable energy in the region. Funding vehicle examples include the Scaling Up Renewable Energy Program in Low Income Countries (SREP) and the Clean Technology Fund (CTF), which have been involved in implementing hundreds of varied projects. The budgets from these vehicles are however very small; for instance, SREP had a budget of $€ 14$ million and CTF also has contributed US $\$ 5.4$ billion to projects globally spread over different initiatives ranging from transport to electricity. In terms of renewable projects, only $10 \%$ of the CTF funding is directed towards Africa [11]. It can thus be appreciated that the donor-funding path, although very important, will not accelerate the rate of renewable energy uptake and rapidly increasing access to electricity [12].

Ultimately, to move to large-scale renewable independent power producer (IPP) investments, there needs to be a diversification of funding to include a larger role for private capital and loans, and this requires governments to play a more active role [12]. There is a need for support in the form of government guarantees; however, governments are faced with many other challenges and are therefore reluctant or unable to provide such guarantees to IPPs according to SAPP [7].

In cases where such guarantees are provided, success has been achieved; for instance, in South Africa, there is an ongoing program sanctioned by the government called the Renewable Energy Independent Power Producer Programme (REIPPPP). The South African government provides the necessary guarantees and the program is underpinned by the Integrated Resource Plan (IRP) of the country which evaluates the energy needs of the country and proposes an optimal energy mix. Additionally, the energy generated by IPPs is on a take-or-pay basis, meaning that the national power company, Eskom, is obliged to buy the power whenever it is available.

Over US\$19 billion has been invested as a result of this program; local and international banks provide funding directly to the IPPs based on the bankability of the projects backed by guarantees from the government [13].

A similar model should be considered by SAPP where resources are assessed at a regional level, and an optimal mix should be determined at that level. SADC can then decide on a guarantee mechanism that commits each government according to the benefits derived. In order for this to happen, significant reform at SAPP level is required as discussed in "Institutional and Policy."

Other innovative solutions to address the financial challenges have already been proposed by SAPP. For example, a feed-in premium (FIP) subsidy, which will support projects which were identified in a competitive bidding process, but are above the benchmark levelized cost of energy (LCOE) [14] and cannot be funded from the proposed clean energy fund intended for SAPP (CEF4SAPP).

It can be concluded that for a country to promote largescale renewable energy implementation, there needs to be 
government commitment in the form of long-term financial guarantees to IPPs, power purchase agreements (PPA) on a take-or-pay basis, and proper energy resource planning in the form of integrated resource plans.

\section{Grid Design}

In order to deploy renewable energy on a large scale and facilitate regional trade, a strong transmission grid is required [15]. Lack of adequate transmission and distribution infrastructure was identified as one of the main impediments to regional integration $[16 \bullet \cdot]$. Due to the spatial diversity of renewable resources, it is recommended that a regionally coordinated strong transmission network be developed to enable resource sharing [17]. In SAPP's own assessment, transmission capacity constraints affect bi-lateral and day-ahead energy trading among member countries [18]. To strengthen the existing regional grid will alone require an investment of approximately US\$18 billion [19•].

To achieve this, the SAPP Pool Plan (which is a regional generation and transmission expansion plan) identified a number of priority projects to be prepared, to be implemented, and to facilitate cross-border energy trade [20]. It is also recommended that SAPP should pursue cross-border transmission projects and establish the interconnections to Angola, Malawi, and Tanzania, which are currently not interconnected to the SAPP grid [6], at a cost of approximately US $\$ 3$ billion [21]. The priority regional projects are illustrated in Fig. 1 which aim to strengthen the existing interconnections and integrate new generation.

HVDC is strongly recommended as a means to facilitate cross-border interconnections to benefit the region from largescale renewable energy projects. Renewable energy resources, other than hydro, tend to be dispersed over larger areas with little or no transmission infrastructure. Due to the relatively low cost of hydropower and the high load factors, it is recommended that more focus and emphasis should be placed on developing hydropower and transmission infrastructure $[16 \bullet \bullet$. This power can be transported to other countries in Southern Africa using HVDC and HVAC super-grids.

There are four hydropower priority projects, along with other developments, that SADC has identified, aimed at achieving the region's renewable energy requirements. These are the 1500 MW Mpanda-Nkuwa in Mozambique, the $4800 \mathrm{MW}$ Inga III in the DRC, the $1600 \mathrm{MW}$ Batoka Gorge project between Zambia and Zimbabwe, and the 1200 MW Lesotho Highlands Water Project Phase II in Lesotho [8].

The estimated cost for transmitting power from Inga in the Congo to the Southern-most tip of the region (South Africa) was estimated at US\$0.09 in 2013 [16••].

There is however caution expressed in the use of HVDC. HVDC is not useful in improving access to electricity in rural

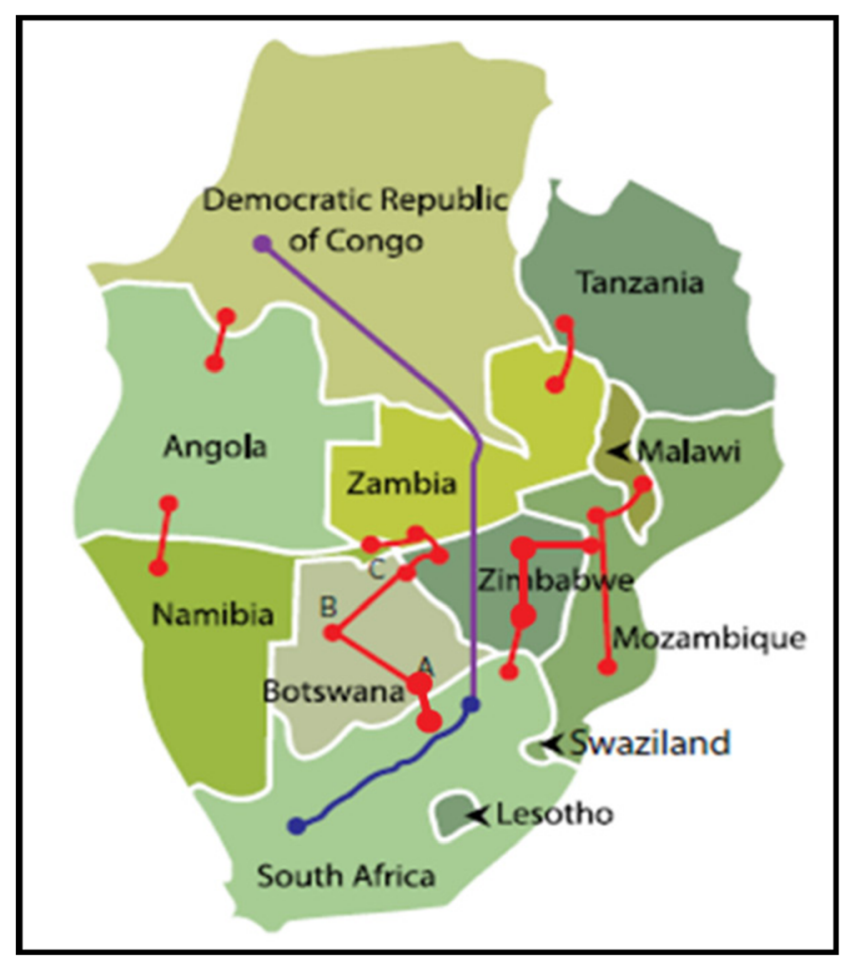

Fig. 1 Priority Regional Transmission Projects (Source: [22])

areas. This is due to the complexities of rural settlements, geographical limitations, and the high costs associated with connecting to the HVDC lines. Off-grid solutions are advocated as a way to harness renewable resources especially PV which is faster to implement for households with no access to the grid [19•].

It is estimated that using grid-connected power to reach around 200 million people by 2030 will cost US $\$ 280$ billion; clearly, the capacity for that kind of funding is limited. It is for this reason that off-grid PV and mini-grids are encouraged as a way to economically address these challenges. The decentralized nature of renewables is seen as a way to achieve strides in rural electrification [19•].

When it comes to harnessing PV, there is no contradiction between off-grid and grid-connected supplies. Instead, these can be easily combined as time progresses. In the long term, an optimal grid consisting of off-grid and mini-grids integrated into a national and regional grid is the optimal solution $[23 \cdot \bullet]$.

\section{Institutional and Policy}

The level of regional cooperation in Sub-Saharan Africa, including SADC, on energy issues has not matured to a level where they have achieved anything meaningful in harmonizing regional energy plans. These organizations need a level of "cross-fertilizing" cooperation, which will assist in increasing access to electricity [24]. There was also a realization that the existing institutions are sufficient and only need to be 
enhanced to achieve maximum benefit. It was recommended that the role of regional institutions be reviewed to have more authority on issues of energy development so that the institution can be the one informing regional energy plans [25].

However, the requirement for new policies and institutions to foster investments into the region was highlighted [16••].

There is also a need for policies that will encourage participation from IPPs in the SADC region, as well as for SAPP and the Regional Electricity Regulators Association of Southern Africa (RERA), to be given more powers to direct energy policies [26].

Ways to improve regional electricity markets' performance focusing on the SAPP region and the need to give RERA more powers and resources in order to oversee regional development were also emphasized. There is reluctance to cede planning authority to SAPP; however, this can be mitigated if members of SAPP were allowed to propose projects to SAPP under the supervision of a newly empowered RERA, who will only approve projects under the following conditions [27]:

- Network costs should be fully recovered

- Costs should be allocated according to benefits

- Projects should not interfere with regional trade

- Separation of network transactions from commercial transactions

- Feasibility of implementation

Government institutions can facilitate better cooperation but are currently perceived to be limiting development. SADC member countries are more focused on achieving energy self-sufficiency than on regional cooperation [25]. Where cooperation exists, it tends to be on a bi-lateral basis with long-term supply contracts [25]. If these are done at the expense of region-wide cooperation, it will be difficult to achieve a cost-effective optimal energy supply for the region. Regional institutions can play a role in addressing this problem, especially if the powers of SAPP are bolstered.

\section{Skills Development}

The level of technical skills and knowledge about renewables plays a role in their adoption. An example of this is the balance between base load and variable generation which is one of the areas not well understood by SAPP member countries [7]. Renewables are not seen as technologies that can sufficiently plug the gap between demand and base-load generation due to their intermittent nature and this may lead to reluctance in investments.

Skills can be developed by means of training interventions and workshops. IRENA has developed tools such as SPLAT [28] and assessments of transmission network capabilities can be done using Plexos ${ }^{\mathrm{TM}}$ as was done by [29] in the Council for
Scientific and Industrial Research (CSIR). These and other advanced optimization tools are necessary to account for the resources.

There are a number of training initiatives taking place in the SAPP region to ensure skills transfer on renewable energy. Some of these initiatives are:

- Workshops hosted by IRENA and Southern African Centre for Renewable Energy and Energy Efficiency (SACREEE) to update the global atlas with a focus on wind and solar zones [30]

- $\quad$ Renewable Energy Training Weeks (RETW) by IRENA to provide support with the integration of renewable generation into power systems in Southern and Eastern Africa. This allows for utilities to share experiences and learn from international best practices [31]

- Country-specific support by GiZ providing similar services as IRENA [32]

- Africa Climate Resilient Investment Facility (AFRI-RES) workshops which assist African utilities to consider climate change into the planning and design of long-term investments [33]

\section{Environment}

In order to quantify the level of pollution and also to participate in green funding initiatives, SAPP concluded a Grid Emission Factor (GEF) study. The study also aims to determine greenhouse gas emission factors for the nine interconnected SAPP countries to allow these countries to participate in the clean development mechanism (CDM) projects. CDM allows countries to obtain green certificates or credits and qualify for funding in the process. It is expected this will further assist with attracting funding into the region.

\section{Conclusions}

The literature scan highlighted the numerous challenges that the region experiences in harnessing renewable resources as an alternative energy source to supply the millions that are left in the dark. The most prevailing challenge pertains to the state of the grid which is not adequate. Three countries that are members of SAPP but are not yet interconnected need to be urgently connected to the SAPP grid. Progress is being made in that regard as there are currently projects that are aimed at achieving this.

The region requires significant investment to unlock its abundant energy potential. Lack of capital is not easy to mitigate and other funding models may be necessary. Although funding is still a major problem, some innovative solutions like CDM projects and FIP are being proposed for 
implementation; the proposed CEF4SAPP will also go some way in improving funding of renewable projects. Donor funding and subsidies are currently assisting in plugging the gap; however, in the long run, governments need to become more willing in providing guarantees to renewable energy projects. These can be done in conjunction with other investments that will be off-takers of the generated energy. In the process, the local population will benefit through access to an increasing level of grid.

A progression from off-grid, to mini-grids and eventually to interconnected national and regional grids, makes more sense for a region like SADC to mitigate for large upfront capital outlay. There is currently appetite from private investors to provide off-grid solutions at their own risk [34]; however, these have to be eventually integrated to mini-grids and national grids. The provision of off-grid by private investors gives breathing space for cash-strapped governments while improving access.

HVDC and hydropower were strongly identified as costeffective ways to rapidly increase renewable energy uptake. While large hydropower projects can deliver huge amounts of reliable power, HVDC interconnectors would enhance renewable electricity trade between power pools with diverse energy mixes. However, there was caution against HVDC which is not easy to tap off from as it is more suited for direct point to point supply without delivering power to remote rural locations along the way.

Proposals aimed at introducing institutional reform have also been made; this is because SAPP is perceived as not being empowered enough to make decisions that will foster renewable adoption or integrated generation plans at regional level. The institution needs to be empowered to make binding decisions that will mitigate for political issues that have been encountered, like the ever-present issue of energy selfsufficiency.

Skills development is also an area that needs further attention; the current training initiatives will go some way in addressing the knowledge gaps and imparting skills and technical expertise to the practitioners within SAPP. Some of the crucial training interventions that are noteworthy pertain to renewable energy integration and resource capacity assessment which are important building blocks for adoption of these technologies. Experience is to be drawn from developed countries to avoid repeating past mistakes.

\section{Compliance with Ethical Standards}

Conflict of Interest The authors declare that they have no conflicts of interest.

Human and Animal Rights and Informed Consent This article does not contain any studies with human or animal subjects performed by any of the authors.
Open Access This article is distributed under the terms of the Creative Commons Attribution 4.0 International License (http:// creativecommons.org/licenses/by/4.0/), which permits unrestricted use, distribution, and reproduction in any medium, provided you give appropriate credit to the original author(s) and the source, provide a link to the Creative Commons license, and indicate if changes were made.

\section{References}

Papers of particular interest, published recently, have been highlighted as:

- Of importance

•- Of major importance

1. IEA, Africa Energy Outlook 2014: a FOCUS ON ENERGY PROSPECTS IN SUB-SAHARAN AFRICA, IEA, 2014.

2.• IRENA. Africa 2030: Roadmap For a Renew Energy Future. IRENA, 2015. A well-structured and comprehensive assessment on renewable energy capacity in the region.

3. Mandelli S, Barbieri J, Mattarolo L, Colombo E. Sustainable energy in Africa: a comprehensive data and policies review. Renew Sust Energ Rev. 2014;37:656-86.

4. Southern African Power Pool. [Online]. Available: http://www. sapp.co.zw/. [Accessed: 20-Jun-2018].

5. Planning Sub-Committee | Southern African Power Pool. [Online]. Available: http://www.sapp.co.zw/coordination-centre/planningsub-committee. [Accessed: 20-Jun-2018].

6. SADC, Protocol on Energy in the SADC Region SADC, Aug1996.

7. Bungane B. Southern African power pool interview with Omar Vajeth. [Online]. Available: https://www.esi-africa.com/powerpool-interview-with-omar-vajeth/. [Accessed: 20-Jun-2018].

8. Southern African Development Community :: Hydropower. [Online]. Available: https://www.sadc.int/themes/infrastructure/en/ hydropower/. [Accessed: 31-Jul-2018].

9. Jadhav AS, Chembe DK, Strauss JM, Van Niekerk JL. Status of solar technology implementation in the Southern African Developing Community (SADC) region. Renew Sust Energ Rev. 2017;73:622-31.

10. World Development Indicators 2017, World Bank Group, Washington, Jun. 2017.

11. Closer Look-CTF, Climate Investment Funds, 14-Dec-2017. [Online]. Available: https://www.climateinvestmentfunds.org/ closer-look/ctf. [Accessed: 30-Aug-2018].

12. Chirambo D. Addressing the renewable energy financing gap in Africa to promote universal energy access: integrated renewable energy financing in Malawi. Renew Sust Energ Rev. 2016;62: 793-803.

13. Eberhard A, Kåberger T. Renewable energy auctions in South Africa outshine feed-in tariffs. Energy Sci Eng. May 2016;4(3): 190-3.

14. SAPP, Southern African Power Pool Monthly Report : April 2018, R04-18, Apr. 2018.

15. Oseni MO and Pollit M. Institutional arrangements for the promotion of regional integration of electricity markets: International Experience. University of Cambridge; 2014.

16.• Sanoh A, Kocaman AS, Kocal S, Sherpa S, Modi V. The economics of clean energy resource development and grid interconnection in Africa. Renew Energy. 2014;62:598-609. Provides insights on the use of HVDC and hydropower. Also encourages institutional reform. 
17. Wu GC, Deshmukh R, Ndhlukula K, Radojicic T, Reilly-Moman J, Phadke A, et al. Strategic siting and regional grid interconnections key to low-carbon futures in African countries. Proc Natl Acad Sci. 2017;114(15):E3004-12.

18. Maviya J. Meeting growing power demands through Southern African regional integration, presented at the Southern African Poer Pool SAREE IRENA Workshop, Windhoek; 2017.

19. Barasa M, Bogdanov D, Oyewo AS, Breyer C. A cost optimal resolution for Sub-Saharan Africa powered by $100 \%$ renewables in 2030. Renew Sustain Energy Rev. 2018;92:440-57. Promotes $P V$ and off-grid as an interim low-cost option.

20. SAPP. Southern African Power Pool Monthly Report: December 2016, R12-16, 2016.

21. SADC. Regional infrastructure development master plan - executive summary, Executive Summary, 2012.

22. Kibido $\mathrm{M}$. The next generation of regional planning considerations for Southern Africa. 2016.

23.• Welsch M, et al. Smart and just grids for sub-Saharan Africa: exploring options. Renew Sustain Energy Rev. 2013;20:336-52. Advocates both off-grid and grid-tied solutions.

24. Mohammed YS, Mustafa MW, Bashir N. Status of renewable energy consumption and developmental challenges in sub-Sahara Africa. Renew Sust Energ Rev. 2013;27:453-63.

25. Montmasson-Clair $\mathrm{G}$ and Deonarain B. Working paper: regional integration in southern Africa: a platform for electricity sustainability TIPS. 2017.
26. Johnson O, Muhoza C, Ogeya M, Lindstrom A, Granit J, Rosner K. Powewring Africa - unlocking opportnunity for energy development in Southern Africa. Stolkholm Environment Institute; 2018.

27. Rose AM. Improving the performance of regional electricity markets in developing countries : the case of the Southern African power. Thesis, Massachusetts Institute of Technology; 2017.

28. Southern African power pool: planning and prospects for renewable energy. [Online]. Available: https://www.irena.org/ DocumentDownloads/Publications/SAPP.pdf. Accessed 20 Jun 2018.

29. Wright J. Over the transmission hurdle: assessing electrical transmission constraints for the Southern African power Pool (SAPP) in PLEXOS. 2014

30. SAPP. Southern African Power Pool Monthly Report: April 2017, R04-17, 2017.

31. SAPP. Southern African Power Pool Monthly Report : October 2015, R10-15, 2015.

32. giz, Renewable energies and energy efficiency for a greener future. [Online]. Available: https://www.giz.de/en/worldwide/17790.html. Accessed 31 Jul 2018.

33. SAPP. Southern African Power Pool Monthly Report: November 2016, R11-16, 2016.

34. Off-grid solar power booms in Africa, How We Made It In Africa, 19-Dec-2016. [Online]. Available: https://www. howwemadeitinafrica.com/off-grid-solar-power-booms-africa/ 57033/. Accessed 28 Aug 2018. 